\title{
Middle ear resonance in infants: Age effects
}

\author{
Karina Delgado André', Seisse Gabriela Gandolfi Sanches², Renata Mota Mamede Carvallo3. \\ 1) Specialized in Audiology. Audiologist. \\ 2) $\mathrm{PhD}$. Audiologist. \\ 3) $\mathrm{PhD}$. Associate Professor FMUSP. \\ Institution: Departamento de Fisoterapia, Fonoaudiologia e Terapia Ocupacional da Faculdade de Medicina da Universidade de São Paulo (FMUSP). \\ São Paulo / SP - Brazil \\ Mailing address: Renata Mota Mamede Carvallo - Rua Cipotânea, 51 - Cidade Universitária - São Paulo / SP - Brazil - Zip code: 05360-160. E-mail: renamaca@usp.br \\ Article received in December 19, 2011. Article approved in February 5, 2012.
}

\section{SUMMARY}

Introduction: The resonant frequency is the probe frequency in which susceptance is 0 due to the neutralization of the forces of mass and stiffness components that control the middle ear. This frequency can be evaluated by multifrequency tympanometry, and the normality value for adults ranges $800-1,200 \mathrm{~Hz}$. Studies about resonant frequency in children are scarce.

Aim: Identify the variation of the resonant frequency in infants between the first days after birth and the third month of life. Method: Prospective study. Thirty newborns were evaluated at 2 different times: at the neonatal phase up to 12 days of life, and between 72 and 84 days of life. In the first evaluation, we carried out otoacoustic emissions and identified the resonant frequency, and identified the resonant frequency again in the second evaluation.

Results: In the first evaluation, we determined a mean resonance value of $250 \mathrm{~Hz}$ for both ears, while that in the second evaluation was $385 \mathrm{~Hz}$. In both assessments, we found no significant differences between the ears. There was a significant difference between the first and second evaluation.

Conclusion: The middle ear resonant frequency in infants is lower in the first days of life due to the influence of the mass component. The present study demonstrated that the resonance frequency increased in the first months of life.

Keywords: acoustic impedance tests, hearing tests, infant.

\section{INTRODUCTION}

The transmission of sound from the ear canal to the cochlea is mediated by the ossicular mass, stiffness of the tympanic membrane, the ligaments and tendons that support the middle ear, air, and by friction, all of which generate a rate of impedance to the sound that reaches the cochlea. Although friction acts uniformly on that energy transfer, the influence exerted by the ossicular mass and tympanic membrane stiffness can increase or decrease in function of the frequency transmitted. However, the effects of mass and stiffness are mutually canceling at a particular middle ear resonant frequency. That frequency can be determined by means of multifrequency tympanometry, a test that can be performed with a middle ear analyzer. The tympanogram obtained with the resonant frequency of the middle ear is generally a double-peaked tympanogram $(1,2)$.

Experimental data have shown that changes in the middle ear alter the tympanograms obtained with higher probe frequencies, shifting the resonant frequency of the middle ear transmission system. Increased stiffness (due to otosclerosis, for instance) can increase the resonant frequency of the middle ear up to nearly $1,400 \mathrm{~Hz}$, higher than that expected for the normal population (3-5). In contrast, an increase in the mass effect due to ossicular discontinuity or otitis media with effusion can shift the resonant frequency of the middle ear to lower frequencies (6-11). Kontrogiann et al. (12) found a mean resonant frequency of $499 \mathrm{~Hz}$ in children suffering from otitis media with effusion.

Multifrequency tympanometry is more appropriate than traditional single-frequency tympanometry to detect small changes in the transmission characteristics of the tympano-ossicular system.

The resonant frequency is the probe frequency at which susceptance becomes 0 because of the counteractive forces of its mass and stiffness components. The normal resonant frequency has been reported to range 600-1,340 $\mathrm{Hz}(8,13)$, with a mean resonant frequency of approximately $1,000 \mathrm{~Hz}$ having been reported in normal adults $(14,15)$. Most studies investigating the resonant frequency of the middle ear have involved adults. Colleti (6) showed that the resonant frequency ranges $600-1,340 \mathrm{~Hz}$. SHanks (13) reported that the values range $800-1,200 \mathrm{~Hz}$. FunASAKA et al. (9) established normative data for the resonant frequency (720-1,880 Hz). VALVIK (14) found a mean resonant frequency of $1,049 \pm 261 \mathrm{~Hz}$, whereas Carvallo (15) found values ranging 600-1,350 Hz (mean, $959.57 \mathrm{~Hz}$ ).

Studies involving children are scarce. A study investigating children in the 6-15 year age bracket found 
that the resonant frequency ranged 650-1,400 Hz-the mean frequency being approximately $1,000 \mathrm{~Hz}$ - and that there was no relationship between the resonant frequency and sensorineural hearing loss (16).

The external and middle ear systems vary significantly in their acoustic response properties over the first 2 years after birth (17). In that period, the external auditory meatus increases in size, the orientation of the tympanic membrane changes, and the middle ear mass decreases, among other changes. Holte et al. (18) reported that the external auditory meatus wall and middle ear mobility change in the first 4 months of life, as do the tympanometric characteristics. Those authors also reported that, because the middle ear of children is a mass-dominated system, the resonant frequency in children tends to be lower than in normal adults, in whom the middle ear system is stiffnessdominated.

The resonant frequency is a measurement that has largely been related to otoacoustic emissions (OAEs). Any change in the transmission efficiency of the middle ear may hinder the achievement of cochlear responses, especially for low-frequency sounds (19). It is believed that evoked OAEs are best detected at the middle ear resonant frequency $(0.8-1.5 \mathrm{kHz}$, at which there is a greater response amplitude), given that the tympanic membrane vibrates with the greatest displacement amplitude when transmitting sound energy from the external auditory meatus to the cochlea $(11,20,21)$.

The infant middle ear is known to be a massdominated system, and known factors can alter test results. However, few studies have been conducted to determine the resonant frequency in infants. In addition, the study of middle ear resonant frequency in infants could further understanding of the double-peaked tympanograms that are often seen in infants submitted to tympanometry with a probe tone frequency of $226 \mathrm{~Hz}$. Studies have shown that double-peaked tympanograms are seen in approximately $60 \%$ of neonates $(22,23)$. The objective of the present study was to determine the variation in infant middle ear resonant frequency between the first days of life and the third month of life.

\section{MetHOD}

This was a prospective study involving data collected for individual ears (i.e., 2 datasets per subject). We evaluated 28 neonates (16 girls and 12 boys). The infants were evaluated at 0-2 weeks of age (first evaluation) and at 23 months of age (second evaluation). All 28 neonates underwent the first evaluation. However, only 21 infants (12 girls and 9 boys) underwent the second evaluation (at
72-84 days of age). Written informed consent was obtained from all mothers whose infants were evaluated at least once. The local research ethics committee approved the study (Protocol No. 174/01).

The inclusion criterion was the presence of transient evoked OAEs (TEOAEs). The exclusion criterion was presenting with risk factors for hearing loss in accordance with the 2007 Joint Committee on Infant Hearing guidelines (24). We identified the risk factors for hearing loss by analyzing the medical records of the infants and asking their parents about consanguinity and a family history of hearing loss. The infants who met the inclusion criteria underwent middle ear resonant frequency evaluation.

\section{Equipment}

For TEOAE testing, we used an Echoport Plus ILO292 otoacoustic emission analyzer (Otodynamics Ltd., Hatfield, UK) in the QuickScreen mode, which is the mode recommended for newborn hearing screening. The QuickScreen mode features standard nonlinear click stimuli, each consisting of 4 pulses: 3 pulses of equal amplitude and polarity; and one inverted polarity pulse, the amplitude of which is 3 times greater than that of the first 3 . The tests were performed with a response time window of $12 \mathrm{~ms}$. The transient stimuli consisted of $80-\mu$ s clicks delivered at a peak equivalent sound pressure level of 78-83 dB. For tympanometry, we used a middle earanalyzer (GSITympStar, version 2; Grason-Stadler, Eden Prairie, MN, USA) and the method described by Funasaka and Kumakawa (24).

\section{Procedure}

The neonates were tested in their cradles in a quiet room next to the nursery, preferably while sleeping. Newborn hearing screening (TEOAE testing) was performed in the QuickScreen mode. A probe with a soft rubber tip was inserted into the external auditory meatus in order to record TEOAEs. We considered TEOAEs to be present when the overall reproducibility was e" $50 \%$, reproducibility by frequency was e" $70 \%$, and the amplitude by frequency $(2,3$, and $4 \mathrm{kHz})$ was e"6 $\mathrm{dB}$.

After confirming the presence of TEOAEs, we performed middle ear resonant frequency testing in accordance with the method described by FunAsaka and KumaKawa (25). Each ear underwent to a sequence of tests. For the first test, the probe tone was swept through a series of frequencies that automatically ranged 250-2,000 Hz at $50-\mathrm{Hz}$ intervals, and a pressure of $+200 \mathrm{daPa}$ was simultaneously introduced into the external auditory meatus. Immittance and phase measurements were stored in the 
memory of the middle ear analyzer. The first tympanogram was recorded in the acousticadmittance mode at a frequency of $226 \mathrm{~Hz}$. Equivalent ear canal volume, peak admittance, and tympanometric width (or equivalent middle ear volume) values were then registered. The probe tone was again swept through the abovementioned series of frequencies $(250-2,000 \mathrm{~Hz})$ at the 226-Hz tympanometric peak pressure. Immittance and phase measurements were again stored in the memory of the middle ear analyzer. The differences between the first and second frequency sweeps in terms of the immittance and phase values were calculated and registered on the screen in function of the frequency range $(250-2,000 \mathrm{~Hz})$. This constituted the second test. The resonant frequency of the ear tested was automatically identified by the screen cursor. For the third test, the resonant frequency was used as the probe tone frequency for a new tympanogram. A double-peaked tympanogram is expected when the probe tone frequency coincides with the resonant frequency of the ear tested $(1,2)$.

In the second evaluation, which was performed at age $2-3$ months, the infants were again submitted to the battery of middle ear resonant frequency tests in order to determine the variation in resonant frequency in function of age.

The data were analyzed by analysis of variance for the statistical analysis. The level of significance was set at $\mathrm{p}<0.05(5 \%)$.

\section{RESULTS}

Table 1 depicts the comparison between the right and left ears in terms of their resonant frequency (in $\mathrm{Hz}$ ) in each evaluation. We found no statistically significant differences between the right and left ears in either of the evaluations; however, we did find significant differences when we compared the resonant frequency of an ear at age 0-2 weeks with that of the same ear at age 2-3 months (Graph 1).Comparative analysis of the 2 evaluations revealed highly significant differences between the right ear at age 0 2 weeks (first evaluation) and the same ear at age 2-3 months (second evaluation), as well as between the left ear at age $0-2$ weeks and the same ear at age $2-3$ months, in terms of the resonant frequency of the middle ear, with the mean resonant frequencies of the second evaluation being consistently higher than those in the first (Graph 1).

\section{DisCUSSION}

Similar to other tympanometric measurements, determination of the middle ear resonant frequency proved to be an objective, rapid, user-friendly, noninvasive method

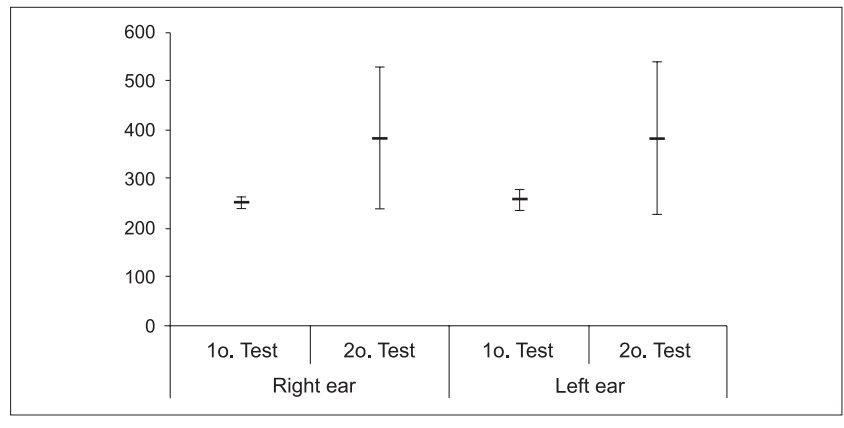

Graph 1. Comparison of the mean $( \pm S D)$ of the resonance frequency $(\mathrm{Hz})$ between the evaluations.

Tabela I. Comparison of the resonance frequency, in both ears, in both evaluations.

\begin{tabular}{|c|c|c|c|c|}
\hline & \multicolumn{2}{|c|}{ 2- 12 days of life } & \multicolumn{2}{|c|}{ 72-84 days of life } \\
\hline & $\begin{array}{l}\text { Right } \\
\text { Ear }\end{array}$ & $\begin{array}{l}\text { Left } \\
\text { Ear }\end{array}$ & $\begin{array}{l}\text { Right } \\
\text { Ear }\end{array}$ & $\begin{array}{l}\text { Left } \\
\text { Ear }\end{array}$ \\
\hline $\begin{array}{l}\text { Media } \\
\text { Median }\end{array}$ & $\begin{array}{c}253,57 \\
250\end{array}$ & $\begin{array}{c}262,50 \\
250\end{array}$ & $\begin{array}{c}385,71 \\
350\end{array}$ & $\begin{array}{c}385,71 \\
350\end{array}$ \\
\hline $\begin{array}{l}\text { Standart } \\
\text { deviation }\end{array}$ & $|3,1|$ & 22,05 & 145,90 & 156,64 \\
\hline Minimum & $\begin{array}{l}250 \\
300\end{array}$ & $\begin{array}{l}250 \\
300\end{array}$ & $\begin{array}{l}250 \\
750\end{array}$ & $\begin{array}{l}250 \\
800\end{array}$ \\
\hline $\begin{array}{l}\text { Maximumo } \\
\mathrm{N}\end{array}$ & $\begin{array}{c}300 \\
28\end{array}$ & $\begin{array}{c}300 \\
28\end{array}$ & $\begin{array}{l}750 \\
21\end{array}$ & $\begin{array}{l}800 \\
21\end{array}$ \\
\hline $\mathrm{p}$-value & \multicolumn{2}{|c|}{$0,07 \mid$} & \multicolumn{2}{|c|}{ I,000 } \\
\hline
\end{tabular}

for determining the state of the middle ear, aiding in the diagnosis of hearing impairment. The resonant frequency aids in establishing a more accurate diagnosis of middle ear changes, revealing the cause of such changes (i.e., decreased or increased mass or stiffness).

Although the parents were informed that the test was rapid and important, some did not consent to the inclusion of their children in the present study or to newborn hearing screening, whereas others did not bring their children for the second evaluation. The dropouts were unrelated to difficulties in returning for the second evaluation, given that all of the babies born in the hospital where the tests were performed were residents of nearby regions.

The resonant frequency for the right and left ears was found to be approximately $250 \mathrm{~Hz}$ in the first evaluation. The tympanograms obtained with the resonant frequency of the middle ear were double-peaked tympanograms, as has been described in the literature $(1,2)$.

As the resonant frequency and double-peaked tympanogram were observed at approximately $250 \mathrm{~Hz}$ in the neonates, it is important to correlate this finding with 
data in the literature demonstrating that a probe frequency of $226 \mathrm{~Hz}$ results in double-peaked tympanograms in neonates $(22,23,26)$. Therefore, when tympanometry is performed with a probe frequency of $226 \mathrm{~Hz}$ in clinical practice, the resulting double-peaked tympanogram might be due the fact that that the probe frequency is extremely close to the middle ear resonant frequency of the infant.

The standard deviation for the right and left ears in the first evaluation (Table 1) was not significant, given that the variation in frequency during the sweeps occurred at 50-Hz intervals. The comparison between the right and left ears in the first evaluation revealed a trend toward significance.

We found that the middle ear resonant frequencies in the infants who returned for the second evaluation were higher, similar to those reported in the literature (16). In those infants, the middle ear resonant frequencies remained highly variable, with a high standard deviation, demonstrating that the resonant frequency is still in transition at approximately 3 months of age (18); however, the mean middle ear resonant frequency was still lower than that reported for adults $(6,9,13-15)$.

The comparison of the resonant frequencies found in the first evaluation with that in the second revealed a highly significant difference. This demonstrates maturation of the middle ear in relation to the neonatal period, with the resonant frequency of the middle ear increasing in function of a decrease in mass and ear canal size (17). The difference between neonates and 3-month-old infants in terms of middle ear resonant frequency underscores the importance of using a higher probe tone frequency when performing tympanometry in the neonatal population, as has been previously suggested $(22,24)$. Studies conducted by CALANDruccio et al. (27) and Silva et al. (22) showed that tympanometry with a probe tone frequency of $1,000 \mathrm{~Hz}$ is the most sensitive method for detecting middle ear changes in neonates. The results of the present study show that the middle ear function in infants at approximately 3 months of age is still different from that in adults. This suggests that $1,000 \mathrm{~Hz}$ is the frequency of choice for tympanometry in infants in that age bracket. The results of the present study also corroborate recommendations for the use of tympanometry with a probe tone frequency of $226 \mathrm{~Hz}$ in infants $\geq 6$ months of age (24).

A study investigating acoustic reflectance in neonates showed that reflectance was higher for sounds at frequencies below $2,000 \mathrm{~Hz}$ (28). Structural differences in the external auditory meatus, including size and the presence of vernix caseosa, can partially explain the differences in reflectance and middle ear resonant frequency found in that population.
Further studies are needed in this area, principally in neonates, in order to standardize the value of the middle ear resonant frequency, given that the resonant frequency can facilitate the diagnosis of hearing impairment and aid in hearing screening, with researchers having linked the resonant frequency in adults to OAEs (29).

\section{CONCLUSIONS}

The resonant frequency of the middle ear in neonates is lower than in adults, which is possibly due to a greater influence of mass. The determination of middle ear resonant frequency is a rapid, user-friendly test, the results of which can be of clinical value for the diagnosis of hearing impairment, assisting in the identification of changes in the middle ear.

\section{REFERENCES}

1. Margolis RH, Goycoolea HG. Multifrequency Tympanometry in Normal Adults. Ear\&Hear, 1993; 14(6):408-13.

2. Carvallo RMM. Fonoaudiologia - Informação para formação. Procedimentos em Audiologia. 2003. Rio de Janeiro. Guanabara Koogan, p. 1-22.

3. Colletti V, Fiorino FG, Sittoni V, Policante Z. Mechanics of the middle ear in otosclerosis and stapedoplasty. Acta Otolaryngol, 1993; 113(5):637-641.

4. Frade C, Lechuga R, Castro C, Labella T. Análisis of the resonant frequency of the middle ear in otosclerosis. Acta Otorrinolaryngol Esp, 2000; 51(4):309-313.

5. Miani C, Bergamin AM, Barotti A, Isola M. Multifrequency multicomponent tympanometry in normal and otosclerotic ears. Scand Audiol, 2000; 29(4):225-237.

6. Colletti V. Methodologic observations on tympanometry with regard to the probe-tone frequency. Acta Otolaryngol, 1975; 80:54-60.

7. Colletti V. Tympanometry from 200 to $2000 \mathrm{~Hz}$ probe tone. Audiology, 1976; 15:106-119.

8. Colletti V. Multifrequency tympanometry. Audiology, 1977; 16:278-287.

9. Funasaka S, Funai H, Kumakwa K. Sweep frequency tympanometry: Its development and diagnostic value. Audiology, 1984; 23:366-379.

10. Levina Lu V, Ivanets IV. Diagnostic implications of 
examination of middle ear resonance frequency. Vestn. Otorrinolaringol, 2002; 2:11-13.

11. Zhao F, Wada H, Koiki T, Stephens D. The influence of middle ear disorders on otoacoustic emissions. Clinical Otolaryngology and Allied Sciences., Feb 2002; 25(1):38.

12. Kontrogianni A, Feredidis E, Ntouniadakis E, Psarommatis I, Apostolopoulos N, Adamopoulos G. Multiple-frequency tympanometry in children with otites media with effusion. ORL, 1996; 58:78-81.

13. Shanks JE. Tympanometry. Earand Hearing, 1984; 5:268280 .

14. Valvik B, Johnsen M, Laukli E. Multifrequency tympanometry. Audiology, 1994; 33:245-253.

15. Carvallo RMM. Ressonância de orelha média através da timpanometria em multifrequência. Rev. Bras. Med. Otorrinolaringol, jul 1997; 4(4):132-137.

16. Hanks WD, Rose KJ. Middle ear resonance and acoustic immitance measures in children. J Speech Hear Res, 1993; 36:218-222.

17. Keefe DH, Levi E. Maturation of the middle ear external ears: acoustic power-based responses and reflectance tympanometry. Ear and Hearing, 1996; 17:361-373.

18. Holte LA, Margolis RH, Cavanaugh RM. Development changes in multifrequency tympanograms. Audiology, 1991; 30:1-24.

19. Zlumak AI, Kileny PR. Parameters that affect the measurement of otoacoustic emissions. Head Neck Surg, 2001; 9:279-283.

20. Wada H, Ohyma K, Kobayashi T, Sunaga N, Koike T. Relationship between evoked acoustic emissions and middle ear dynamic characteristics. Audiology, 1993; 32:282-292.
21. Wada H, Ohyma K, Kobayashi T, Koiki T, Nogughi S. Effect of middle ear on otoacoustic emissions. Audiology, 1995; 34:61-176.

22. Silva KAL, Novaes BACC, Lewis DR, Carvallo RMM. Achados timpanométricos em neonatos com emissões otoacústicas presentes: medidas e interpretações. Rev. Bras. Otorrinolaringol, 2007; 73(5):633-639.

23. Soares JC, Carvallo RMM. Redução do limiar de reflexo acústico em neonatos sem risco auditivo. Rev. Bras. Otorrinolaringol, 2006; 72(1):49-54.

24. American Academy of Pediatrics, Joint Committee on Infant Hearing. Year 2007 Position Statement: principles and guidelines for early hearing detection and intervention programs. Pediatrics, 2007; 120(4):898-921.

25. Funasaka S, Kumakawa K. Tympanometry Using a Sweep-Frequency Probe Tone and Its Clinical Evaluation. Audiol, 1988; 27:99-108.

26. Margolis RH, Hunter LL. Timpanometria: princípios básicos e aplicações clínicas. In: Musiek FE, Rintelmann WF. Perspectivas atuais em Avaliação Auditiva. 2001, 1ª edição. Barueri. Manole: p. 85-126.

27. Calandruccio L, Fitzgerald TS, Prieve BA. Normative multifrequency tympanometry in infants and toddlers. J Am Acad Audiol, 2006; 17(7):470-80.

28. Sanford CA, Feeney MP. Effects of maturation on tympanometric wideband acoustic transfer functions in human infants. J Acoust Soc Am, 2008; 124(4):2106-22.

29. Couto CM, Carvallo RMM. O efeito da ressonância das orelhas externa e média na captação das emissões otoacústicas. Rev. Bras. Otorrinolaringol, 2009; 75(1):15-23. 